\title{
Tumor Lymphangiogenesis and Metastasis to Lymph Nodes Induced by Cancer Cell Expression of Podoplanin
}

\author{
Leah N. Cueni, ${ }^{*}$ Ivan Hegyi, ${ }^{\dagger}$ Jay W. Shin, ${ }^{*}$ \\ Andrea Albinger-Hegyi, ${ }^{\ddagger}$ Silke Gruber, ${ }^{\S}$ \\ Rainer Kunstfeld, ${ }^{\S}$ Holger Moch, ${ }^{\text {TI }}$ \\ and Michael Detmar*

\begin{abstract}
From the Institute of Pharmaceutical Sciences," Swiss Federal Institute of Technology (ETH) Zurich, Switzerland; the Department of Dermatology, ${ }^{\dagger}$ Inselspital Bern, University Hospital, and University Head and Neck Surgery, and the Department of Pathology, ${ }^{\text {Tा }}$ Institute of Surgical Pathology, University Hospital Zurich, Zurich, Switzerland; and the Department of Dermatology, ${ }^{\complement}$ Medical University of Vienna, Vienna, Austria
\end{abstract} \\ of Bern, Bern, Switzerland; the Department of Oto-Rhino-Laryngology, ${ }^{\ddagger}$
}

The membrane glycoprotein podoplanin is expressed by several types of human cancers and might be associated with their malignant progression. Its exact biological function and molecular targets are unclear, however. Here, we assessed the relevance of tumor cell expression of podoplanin in cancer metastasis to lymph nodes, using a human MCF7 breast carcinoma xenograft model. We found that podoplanin expression promoted tumor cell motility in vitro and, unexpectedly, increased tumor lymphangiogenesis and metastasis to regional lymph nodes in vivo, without promoting primary tumor growth. Importantly, high cancer cell expression levels of podoplanin correlated with lymph node metastasis and reduced survival times in a large cohort of 252 oral squamous cell carcinoma patients. Based on comparative transcriptional profiling of tumor xenografts, we identified endothelin-1, villin-1, and tenascin- $\mathrm{C}$ as potential mediators of podoplanininduced tumor lymphangiogenesis and metastasis. These unexpected findings identify a novel mechanism of tumor lymphangiogenesis and metastasis induced by cancer cell expression of podoplanin, suggesting that reagents designed to interfere with podoplanin function might be developed as therapeutics for patients with advanced cancer. (Am J Patbol 2010, 177:1004-1016; DOI: 10.2353/ajpath.2010.090703)

Podoplanin is a small mucin-type transmembrane glycoprotein that, in normal human tissues, is expressed by diverse cell types, including kidney podocytes, ${ }^{1}$ lung alveolar type I cells, ${ }^{2}$ and lymphatic endothelium. ${ }^{3}$ Studies in podoplanin knockout mice demonstrated that podoplanin is essential for the development of the lung and the lymphatic vascular system. ${ }^{4,5}$ Besides these important physiological functions, podoplanin appears to have a role in cancer pathogenesis. Podoplanin expression was found to be up-regulated in mouse skin during wound healing and chemically induced skin carcinogenesis, ${ }^{6}$ as well as in several human cancers, including squamous cell carcinomas of different organs, ${ }^{7-9}$ mesotheliomas, ${ }^{10}$ certain germ cell tumors, ${ }^{7}$ and tumors of the central nervous system. ${ }^{11}$ Several studies indicated that the expression of podoplanin in tumors might be related to their malignant progression. High levels of podoplanin expression were detected in highly metastatic clones of mouse colon adenocarcinoma and melanoma cell lines, compared with parental cells. ${ }^{12,13}$ Also, data from studies of some human cancers suggested a possible association of podoplanin expression with invasion and metastasis of tumors. ${ }^{14,15}$ The exact molecular function of podoplanin in cancer cells, however, remained unclear.

Podoplanin was shown to be involved in the regulation of cytoskeletal organization and cell motility. Via its short cytoplasmic domain, podoplanin interacts with the membrane cytoskeleton linkers ezrin and moesin, induces formation of filopodia-like plasma membrane extensions, and increases motility in a variety of cell types. ${ }^{4,9,16-18}$ Also, down-regulation of the cell-cell adhesion protein E-cadherin, which is associated with epithelial-mesenchymal transition, was observed in certain cells and tu-

Supported by the National Institutes of Health (CA69184), the Swiss National Fund (3100A0-108207), the Austrian Science Foundation (S9408-B11), Cancer League Zurich, Oncosuisse, Commission of the European Communities (LSHC-CT-2005-518178), all to M.D.; Krebsliga Zurich, and Sassella-Stiftung (I.H.).

Accepted for publication April 6, 2010.

Supplemental material for this article can be found on http://ajp. amjpathol.org

Address reprint requests to Michael Detmar, M.D., Institute of Pharmaceutical Sciences, Swiss Federal Institute of Technology, ETH Zurich, Wolfgang Pauli-Strasse 10, $\mathrm{CH}-8093$ Zurich, Switzerland. E-mail: michael.detmar@pharma.ethz.ch. 
mors in response to podoplanin expression.9,18,19 Together with the localization of podoplanin to the invasive front of tumors, which was observed in human squamous cell carcinomas, ${ }^{7,9,17}$ these data indicate that podoplanin might promote the detachment of tumor cells and the invasion of adjacent tumor stroma, which are crucial steps toward metastasis. Podoplanin also induces the aggregation of platelets ${ }^{20}$ and could thereby facilitate the arrest, extravasation and subsequent metastasis of podoplanin-expressing tumor cells circulating in the blood stream. ${ }^{21}$

The relevance of podoplanin to cancer spread via the lymphatic system, however, has not been clarified. In the present study, we have assessed the effect of podoplanin on lymphatic metastasis in a human breast carcinoma xenograft model. Surprisingly, we found that podoplanin expressed by tumor cells induced tumor lymphangiogenesis and increased metastasis to regional lymph nodes without promoting primary tumor growth. We also show that high cancer cell expression levels of podoplanin correlate with metastasis to lymph nodes and poor prognosis in patients with oral and oropharyngeal squamous cell carcinomas (OSCC). Importantly, by comparative transcriptional profiling of tumor xenografts, we identify novel potential molecular mediators of podoplanin-induced effects.

\section{Materials and Methods}

\section{Generation of Podoplanin-Overexpressing MCF7 Cell Clones and Cell Culture}

MCF7 human breast carcinoma cells were cultured in Dulbecco's modified Eagle's medium (DMEM) containing $10 \%$ fetal bovine serum (FBS) and antibiotics (all from Gibco, Grand Island, NY). A clone of MCF7 cells stably expressing the pTet-Off-regulator plasmid (Clontech, Mountain View, CA) was kindly provided by Dr. Sam W. Lee (Massachusetts General Hospital, Boston, MA). Cells were transfected with the pTRE2hyg response plasmid (Clontech) containing or not full-length cDNA of human podoplanin (GenBank Accession number NM_006474; Origene, Rockville, MD). Stably transfected cell clones were

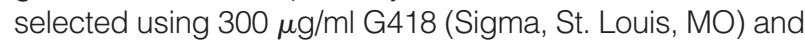
$130 \mu \mathrm{g} / \mathrm{ml}$ hygromycin B (Calbiochem, San Diego, CA). Primary dermal human lymphatic and blood vascular endothelial cells were isolated and cultured as described. ${ }^{22}$

\section{Real-Time Reverse Transcription-PCR}

RNA was isolated from subconfluent cell cultures using TRIzol reagent (Invitrogen, Carlsbad, CA) or from tumor tissue using the EZ1 RNA Universal Tissue Kit (Qiagen, Hilden, Germany) and reverse transcribed using the High Capacity cDNA Reverse Transcription Kit (Applied Biosystems, Foster City, CA). Real-time PCR was performed using the TaqMan Universal PCR Master Mix or the Power SYBR Green PCR Master mix (Applied Biosystems), in a 7900HT Fast Real-Time PCR system (Applied Biosystems). $\beta$-actin served as internal control for normalization of signals.
TaqMan-based real-time PCR was performed for human podoplanin (forward primer 5'-AGGCGGCGTTGCCAT-3'; reverse primer 5'-GTCTTCGCTGGTTCCTGGAG-3'; probe 5'-FAM-CCAGGTGCCGAAGATGATGTGGTG-BHQ1-3'), human vascular endothelial growth factor (VEGF)-C (forward primer 5'-CACCACCAAACATGCAGCTG-3'; reverse primer 5'-TGAAAATCCTGGCTCACAAGC-3'; probe 5'FAM-CGGCCATGTACGAACCGCCAG-BHQ1-3') and human $\beta$-actin (forward primer 5'-TCACCGAGCGCGGCT-3'; reverse primer 5' - TAATGTCACGCACGATTTCCC-3'; probe 5'-JOE-CAGCTTCACCACCACGGCCGAG-BHQ13'). Sybr Green-based real-time PCR was performed for human endothelin-1 (forward primer $5^{\prime}$-ACTTCTGCCACCTGGACATC-3'; reverse primer 5'-CTCTTGGACCTAGGGCTTCC-3), human villin-1 (Hs_VIL1_1_SG QuantiTect Primer Assay, Qiagen), mouse tenascin-C (Mm_Tnc_1_SG QuantiTect Primer Assay; Qiagen), human endothelin receptor B (Hs00240747_m1; Applied Biosystems), or human endothelin receptor A (Hs00609865_m1; Applied Biosystems). Cycling parameters were as follows: 2 minutes at $50^{\circ} \mathrm{C}, 10$ minutes at $95^{\circ} \mathrm{C}$, followed by 40 cycles of 15 seconds denaturation at $95^{\circ} \mathrm{C}$ and 1 minute annealing and extension at $60^{\circ} \mathrm{C}$. All reactions were performed in triplicates.

\section{Protein Extraction, Immunoprecipitation, and Immunoblots}

Proteins were extracted from cultured cells for 30 minutes on ice using cell lysis buffer containing $20 \mathrm{mmol} / \mathrm{L}$ Tris$\mathrm{HCl} \mathrm{pH} \mathrm{7.4,} 150 \mathrm{mmol} / \mathrm{L} \mathrm{NaCl}, 5 \mathrm{mmol} / \mathrm{L}$ EDTA, 1\% Triton $\mathrm{X}-100,25 \mathrm{mmol} / \mathrm{L} \mathrm{NaF}, 1 \mathrm{mmol} / \mathrm{L} \mathrm{PMSF}, 1 \mathrm{mmol} / \mathrm{L} \mathrm{NaVO}_{3}$, $10 \%$ glycerol, and a protease inhibitor cocktail. To extract protein from tumors, tissues were homogenized in lysis buffer (Ray Biotech, Norcross, GA) supplemented with protease inhibitor cocktail, followed by incubation for 30 minutes on ice. Endothelin receptor B was immunoprecipitated from endothelial cell lysates (500 $\mu \mathrm{g}$ total protein) using a sheep polyclonal antibody (Abcam, Cambridge, UK). Immunoblotting was performed using antibodies against human villin-1 (0.56 $\mu \mathrm{g} / \mathrm{ml}$; Sigma), human podoplanin (D2-40, 1:1000; Covance, Emeryville, CA), human RhoA (1 $\mu \mathrm{g} / \mathrm{ml}$; BD Transduction Laboratories, Lexington, $\mathrm{KY}$ ), human endothelin receptor $\mathrm{B}(\mathrm{Ab}$ cam) or $\beta$-actin (clone AC-15, 1:5000; Sigma), and corresponding HRP-coupled secondary antibodies (GE, Little Chalfont, UK). All blocking and antibody incubation steps were performed in 5\% nonfat dry milk in PBS, except for the detection of RhoA, for which blocking and primary antibody incubation were done in $10 \%$ bovine serum albumin (BSA) in PBS. For detection, the ECL Plus Detection System (GE) was used.

\section{RhoA Activity Assay}

Protein was extracted from cultured cells at approximately $30 \%$ confluency, for 5 minutes on ice. Cell lysis buffer was used, containing $50 \mathrm{mmol} / \mathrm{L}$ Tris- $\mathrm{HCl} \mathrm{pH} 7.5$, $150 \mathrm{mmol} / \mathrm{L} \mathrm{NaCl}, 2.5 \mathrm{mmol} / \mathrm{L} \mathrm{MgCl}_{2}, 2.5 \mathrm{mmol} / \mathrm{L} \mathrm{CaCl}{ }_{2}$, $0.1 \%$ sodium dodecyl sulfate, $0.5 \%$ sodium deoxy- 
cholate, 1\% NP-40, $1 \mathrm{mmol} / \mathrm{L} \mathrm{NaF}, 0.1 \mathrm{mmol} / \mathrm{L} \mathrm{PMSF}, 2$ $\mathrm{mmol} / \mathrm{L} \mathrm{NaVO}_{3}$, and a protease inhibitor cocktail. GTPbound RhoA was precipitated from $1.5 \mathrm{mg}$ of total protein by incubation with $50 \mu \mathrm{g}$ Rhotekin-RBD-coupled agarose beads (Cytoskeleton, Denver, CO) for 1.5 hours at $4^{\circ} \mathrm{C}$.

\section{Migration and Proliferation Assays}

Two-chamber migration assays were performed using HTS FluoroBlok Insert System multiwell plates (pore size $8 \mu \mathrm{m}$; BD, Franklin Lakes, NJ) as described. ${ }^{23}$ The underside of the insert membranes was coated with 10 $\mu \mathrm{g} / \mathrm{ml}$ fibronectin (BD) or $50 \mu \mathrm{g} / \mathrm{ml}$ type-I collagen (Inamed, Fremont, $\mathrm{CA}$ ) in PBS, followed by blocking with $100 \mu \mathrm{g} / \mathrm{ml} \mathrm{BSA}$ in PBS. Subconfluent cells were harvested with accutase (Sigma) and $2.5 \times 10^{4}$ cells per well in $50 \mu \mathrm{l}$ DMEM (MCF7, 96-well plate) or $10^{5}$ cells per well in $100 \mu \mathrm{l}$ endothelial cell basal medium (Lonza, Walkersville, MD; endothelial cells, 24-well plate) containing $0.2 \%$ BSA were seeded into the upper chambers of the FluoroBlok plate. The lower chambers contained DMEM or endothelial cell basal medium with $0.2 \%$ BSA and recombinant human endothelin-1 (American Peptide, Sunnyvale, CA) or recombinant human VEGF-A (kindly provided by the National Cancer Institute, Bethesda, MD) where indicated. After 4 to 5 hours at $37^{\circ} \mathrm{C}$, cells on the underside of the membrane were stained with $3.85 \mu \mathrm{g} / \mathrm{ml}$ calcein AM (Fluka, Buchs, Switzerland) in PBS and fluorescence was measured at $485 \mathrm{~nm}$ (ex) and 538 $\mathrm{nm}(\mathrm{em})$ using a SpectraMax Gemini EM plate reader (Molecular Devices, Sunnyvale, CA). Alternatively, migration was assessed by inflicting two right-angled scratches on confluent monolayers of cells, grown in 24-well cell culture plates, using a pipette tip. Images of the intersection of the two scratches were taken at $5 x$ magnification, immediately after scratching and after 48 hours incubation under normal growth conditions, using an Axiovert 200M inverted microscope equipped with an AxioCam MRm camera (Zeiss, Göttingen, Germany). The cell-free area was measured in each image using Adobe Photoshop CS3 software. For proliferation assays, 1000 cells per well were seeded into fibronectin-coated 96-well cell culture plates (Corning, Corning, NY) in normal growth medium. The following day, FBS concentration was reduced to $1 \%$ for 24 hours, before addition of recombinant human endothelin-1 and/or recombinant human VEGF-A. After 48 hours, cells were stained with 50 $\mu \mathrm{g} / \mathrm{ml}$ 4-methylumbelliferyl heptanoate (Sigma) in PBS and fluorescence intensity, proportional to the number of live cells, was measured at $355 \mathrm{~nm}$ (ex) and $450 \mathrm{~nm}$ (em). Average background fluorescence of empty wells was substracted from all values. The unpaired Student's $t$-test was performed for statistical analysis of the results of all assays.

\section{Tumor Xenografts in Nude Mice}

MCF7 human breast carcinoma cells $\left(1.5 \times 10^{7}\right)$, in a 1:1 mixture of serum-free DMEM and Cultrex basement membrane extract (R\&D Systems, Minneapolis, MN), were injected bilaterally into the mammary fatpads of 7to 9-week-old female BALB/cA nude mice (Taconic, Lille Skensved, Denmark). The total injection volume was 0.2 $\mathrm{ml}$. At the same time, 60 -day release $17 \beta$-estradiol pellets (0.72 mg; Innovative Research of America, Sarasota, CA) were implanted subcutaneously in the interscapular regions of mice. Three cell clones that overexpressed podoplanin (PDPN) and three control cell clones (CTRL) were each injected into five mice. Tumor volumes (V) were calculated as $V=0.4 \times L \times W^{2}$, where $L$ is the largest diameter and $\mathrm{W}$ the diameter perpendicular to $\mathrm{L}$. Tumors were grown for 24 days before mice were euthanized and primary tumors and axillary lymph nodes were collected, embedded in O.C.T. compound (Sakura, Zoeterwoude, Netherlands), and frozen. All animal experiments were approved by the Kantonales Veterinäramt Zürich.

\section{Immunohistochemistry, Immunofluorescence, and Analysis of Tumor Vascularization}

Cryosections $(7 \mu \mathrm{m})$ were air-dried and fixed in acetone for 2 minutes at $-20^{\circ} \mathrm{C}$, followed by $80 \%$ methanol for 5 minutes at $4{ }^{\circ} \mathrm{C}$. The primary antibodies used were rabbit anti-human podoplanin $(2 \mu \mathrm{g} / \mathrm{ml}$; Cellsciences, Canton, MA), biotinylated mouse anti-human cytokeratin-18 (2 $\mu \mathrm{g} / \mathrm{ml}$; Acris, Hiddenhausen, Germany), rabbit anti-human villin-1 (0.56 $\mu \mathrm{g} / \mathrm{ml}$; Sigma), rat anti-mouse F4/80 (2 $\mu \mathrm{g} / \mathrm{ml}$; Abcam), rabbit anti-mouse LYVE-1 (2 $\mu \mathrm{g} / \mathrm{ml}$; Angiobio, Del Mar, CA), rat anti-mouse CD31 $(0.3 \mu \mathrm{g} / \mathrm{ml}$; BD Pharmingen, San Diego, CA), and a myc-tagged singlechain $\mathrm{Fv}(\mathrm{scFv}$ ) antibody fragment against the D-domain of human tenascin-C ${ }^{24}$ (scFv[P12], $3 \mu \mathrm{g} / \mathrm{ml}$; kind gift of Dr. D. Neri, Swiss Federal Institute of Technology [ETH] Zurich, Switzerland) followed by an anti-myc antibody (2 $\mu \mathrm{g} / \mathrm{ml}$; GeneTex, San Antonio, TX). For immunofluorescence analyses, Alexa Fluor 488 or 594-conjugated secondary antibodies were used (1:200; Invitrogen Molecular Probes, Eugene, OR) and nuclei were counterstained with Hoechst dye. For immunohistochemistry, biotinylated secondary antibodies $(5 \mu \mathrm{g} / \mathrm{ml}$; Vector, Burlingame, $\mathrm{CA}$ ) were detected using the Vectastain $\mathrm{ABC}$ and the AEC substrate kit (Vector). Images were taken with an Axioskop 2 microscope equipped with an AxioCam MRc camera (Zeiss). Image overlay and morphometric analysis were performed using Adobe Photoshop CS3 software. For analysis of vascularization on LYVE-1 and CD31 double-stained tumor sections, the number and size of blood vessels were determined in three individual hot spot images taken at $10 \times$ magnification for each tumor cross-section. For lymphatic vessels, all vessels that were visible on the tumor cross-section (excluding the skin) were counted and measured. One cross-section was examined for each tumor. For statistical analysis the Mann-Whitney test (lymphatic vessels; no Gaussian distribution of values) or the Student's t-test (blood vessels; Gaussian distribution of values) was used. For detection of metastatic tumor cells, lymph node cross-sections were taken every $100 \mu \mathrm{m}$. 


\section{Tissue Microarray Construction and Analysis}

A tissue microarray was constructed as described ${ }^{25}$ to represent 429 samples of histologically confirmed oropharyngeal or oral squamous cell carcinoma (252 primary tumors, 128 lymph node metastases, 29 recurrent tumors and 20 normal mucosa samples) from previously untreated patients who presented at the Ear, Nose, and Throat Department of the University Hospital Zurich between 1993 and 2000. ${ }^{26}$ Paraffin-embedded tissue samples were obtained from the archives of the Surgical Pathology Department with the approval of the regional board of the Medical Ethics Commission. Immunohistochemistry for podoplanin was performed on 4- $\mu \mathrm{m}$ tissue microarray sections using the D2-40 antibody (1:50; Covance) and a Ventana Benchmark automated staining system (Ventana Medical Systems, Tucson, AZ). The percentage of podoplanin-positive cells (PP) and staining intensity (SI) were evaluated and an immunoreactivity score (IRS) was calculated for each tumor as IRS $=$ PP $\times$ SI. Scores were given as follows: PP $0 \%=0,1 \%$ to $20 \%$ $=1,21 \%$ to $40 \%=2,41 \%$ to $60 \%=3,61 \%$ to $80 \%=4$, $81 \%$ to $100 \%=5$; and SI negative $=0$, weak $=1$, moderate $=2$, strong $=3$. The median IRS of all tumor samples, equaling 1, was used to categorize them into high- (IRS > 1) or low-level podoplanin expression (IRS 0-1). Overall survival and disease-specific survival curves were calculated using the Kaplan-Meier method, with significance evaluated using two-sided log-rank statistics. The relationship between podoplanin expression and clinical and pathological parameters was evaluated using the $\chi^{2}$ test.

\section{Transcriptional Profiling}

Microarray analyses were performed as described, ${ }^{22}$ using $20 \mu \mathrm{g}$ of cRNA per array. Quantile normalization of signals was performed using $R$ software version 2.3.1 (The R Foundation for Statistical Computing) and data were further analyzed using Spotfire software (Tibco, Palo Alto, CA). Signals having a signal-to-noise-ratio of less than three and/or a Flag-value of more than 5000 in at least one of the three replicates of a group (the PDPN group in the case of up-regulated genes, the CTRL group in the case of down-regulated genes) were removed and the unpaired Student's $t$-test was performed for statistical analysis. Hierarchical clustering of genes with a $P$ value of less than 0.05 was performed using the unweighted pair group method with arithmetic mean (UPGMA) and Euclidean distance as similarity measure. The Panther Classification System ${ }^{27}$ was used for functional annotation of genes and comparison of lists of genes that were up- and down-regulated to the whole genome microarray reference list. $P$ values were calculated based on binomial test and Bonferroni-corrected. Microarray data are deposited in the GEO database (http://www.ncbi.n/m.nih. gov/geo/; accessed on May 24, 2010) under accession number GSE14552.

\section{Antibody Array}

Equal amounts of protein from each individual tumor were pooled for all tumors derived from podoplanin overexpressing cells (PDPN) and for all tumors derived from control cells (CTRL). The resulting two samples were each applied to a Human Growth Factor Antibody Array membrane (Ray Biotech) at a concentration of 200 $\mu \mathrm{g} / \mathrm{ml}$, according to the manufacturer's instructions. Detection of chemiluminescence was performed using the ECL Plus Detection System (GE), with an exposure time of 20 seconds. Integrated densities (the sum of the gray values of the pixels in the selection) of each spot were determined using Adobe Photoshop CS3 software, and quantile normalization of the values was performed using $R$ software version 2.3.1 (The R Foundation for Statistical Computing).

\section{Matrigel Plug Assay}

$0.5 \mathrm{ml}$ growth factor-reduced, phenol red-free Matrigel (BD) containing $1 \mu \mathrm{mol} / \mathrm{L}$ human endothelin-1 (Bachem, Bubendorf, Switzerland) dissolved in PBS, or PBS alone, was injected subcutaneously in the inguinal region of female FVB mice (aged 6-7 weeks; Charles River, Sulzfeld, Germany). Four animals were used per group. After 14 days, mice were sacrificed and Matrigel plugs with the overlying skin were excised, embedded in O.C.T. compound (Sakura), and frozen. All animal experiments were approved by the Kantonales Veterinäramt Zürich. Vascularization of the skin overlying Matrigel plugs was analyzed by immunofluorescence as described above. For statistical analysis the Student's t-test was used.

\section{Results}

\section{Podoplanin Overexpression Promotes Migration of MCF7 Breast Carcinoma Cells in Vitro}

To assess the functional significance of podoplanin expression by cancer cells, we ectopically expressed it at high levels in human MCF7 breast carcinoma cells, which completely lack endogenous podoplanin mRNA and protein (Figure 1, A and B). MCF7 cells transfected with the empty vector alone served as control. Podoplanin-overexpressing MCF7 cells more rapidly closed a scratch wound inflicted on a cell monolayer, compared with control cells (Figure 1C), although proliferation rates did not significantly differ between the two cell types in vitro (not shown). Furthermore, levels of active RhoA were decreased in podoplanin-overexpressing cells (Figure 1D). These data indicate that ectopic expression of podoplanin increases the motility of MCF7 breast cancer cells in vitro, likely via down-regulation of RhoA activity. The expression of E-cadherin, as determined by FACS analysis, was weak and did not differ between podoplanin-overexpressing and control MCF7 cells (not shown). 
A

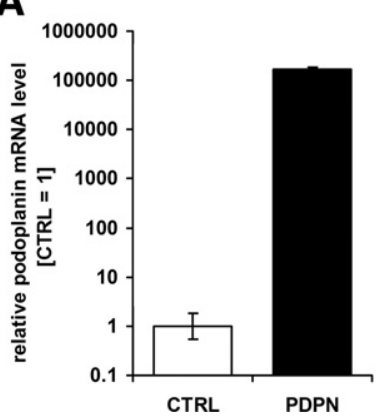

B

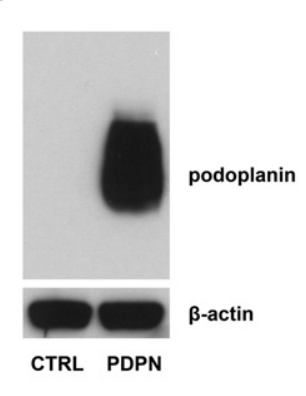

C



D

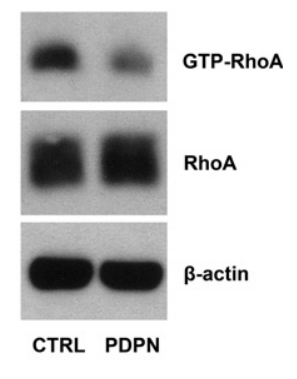

Figure 1. Ectopic expression of podoplanin increases motility of MCF7 breast carcinoma cells. A: Relative human podoplanin mRNA levels, measured by real-time RT-PCR in podoplanin-transfected (PDPN) and control (CTRL) MCF7 cells. Data represent mean \pm SD ( $n=3)$, with the value for CTRL set to 1 . B: Immunoblot detection of human podoplanin in lysates of PDPN and CTRL MCF7 cells. $12 \mu \mathrm{g}$ of total protein were used for each sample and $\beta$-actin served as control for equal loading. C: Closure of a scratch wound inflicted on monolayers of PDPN and CTRL MCF7 cells. The area closed at $t=48$ hours is shown in $\%$ of the initial area at $\mathrm{t}=0$. Data represent mean $\pm \operatorname{SEM}(n=7) .{ }^{* *} P=0.0013$. D: Immunoblot detection of GTP-bound RhoA (from $1.5 \mathrm{mg}$ of total protein) and total RhoA (in 30 $\mu \mathrm{g}$ of total protein) in lysates of PDPN and CTRL MCF7 cells. $\beta$-actin served as control for equal loading.

\section{Podoplanin Overexpression Reduces Primary Tumor Growth in Vivo}

Three MCF7 cell clones stably overexpressing podoplanin (PDPN) and three control cell clones (CTRL) were isolated and xenografted into female nude mice. No differences were observed in overall morphology between the PDPN and CTRL tumors, excised after 24 days of growth. All tumors were interspersed with tumor stroma and contained necrotic areas and extensive immune cell infiltrates (see Supplemental Figure S1 at http://ajp. amjpathol.org). PDPN tumors expressed high levels of podoplanin mRNA and protein, which were undetectable in CTRL tumors (Figure 2, A and B). Unexpectedly, PDPN tumors grew more slowly than CTRL tumors (Figure $2 \mathrm{C}$ ), and the average tumor weight at the time of excision was significantly lower for PDPN tumors than for CTRL tumors $(1.03 \pm 0.08 \mathrm{~g}$ versus $1.54 \pm 0.06 \mathrm{~g}, P<0.0001$; Figure 2D). Thus, overexpression of podoplanin in MCF7 breast carcinoma xenografts does not promote primary tumor growth.

\section{Podoplanin Overexpression Promotes Tumor Lymphangiogenesis and Metastasis to Lymph Nodes}

We next examined the vascularization of tumors by immunofluorescent detection of blood and lymphatic vessels on tumor cross-sections. Whereas blood vessels
A
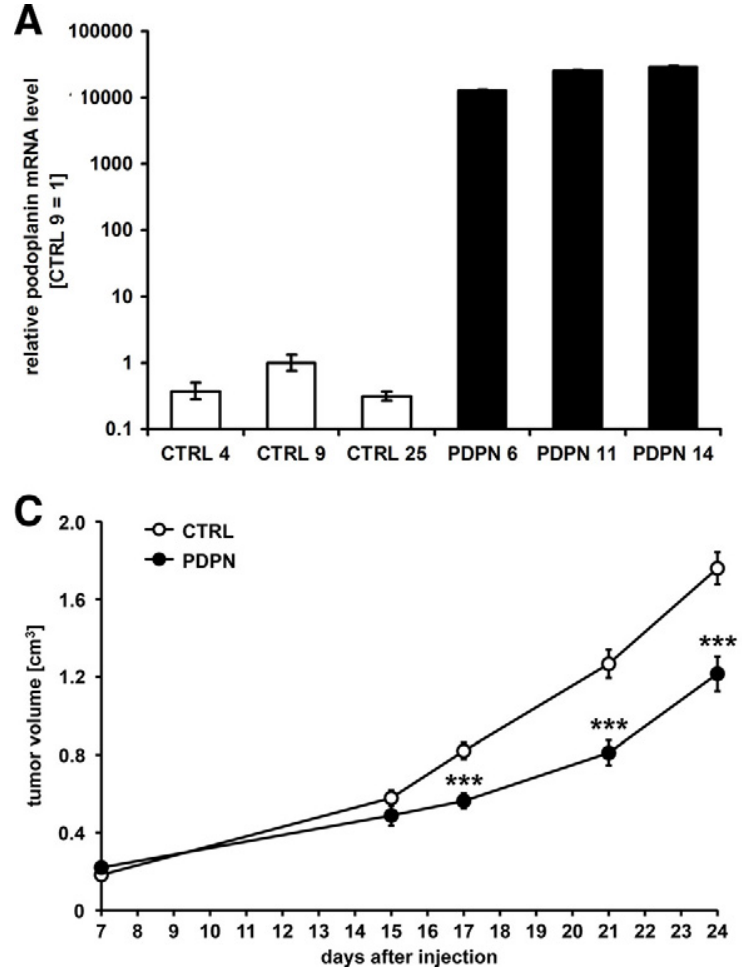

B

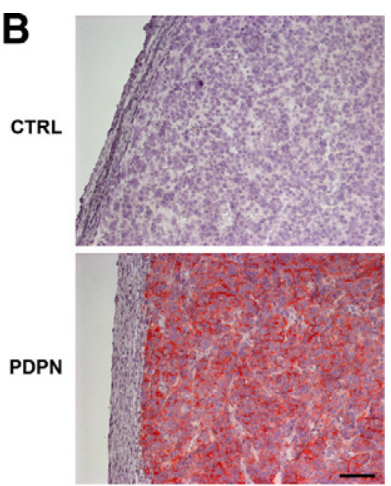

D

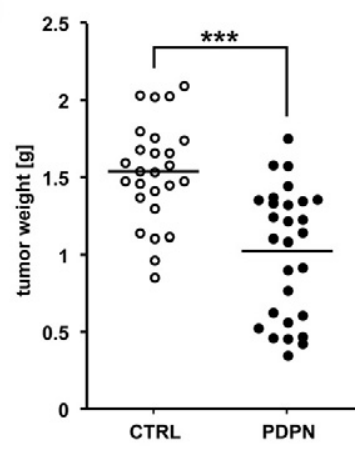

Figure 2. Ectopic expression of podoplanin reduces the growth of MCF7 breast carcinoma xenografts. A: Relative human podoplanin mRNA levels, measured by real-time RT-PCR in MCF7 tumors derived from podoplanin-overexpressing (PDPN) or control (CTRL) cell clones. Data represent mean $\pm \mathrm{SD}(n=3)$, with the value for clone CTRL 9 set to 1 . B: Immunohistochemical detection of human podoplanin in cross-sections of PDPN and CTRL MCF7 tumor xenografts. Scale bar $=100 \mu \mathrm{m}$. C: Growth of PDPN or CTRL MCF7 tumor xenografts in the mammary fat pad of nude mice, before excision at day 24. Data represent mean tumor volumes $\pm \operatorname{SEM}\left(\mathrm{n}_{\mathrm{PDPN}}=28, \mathrm{n}_{\mathrm{CTRL}}=26\right) .{ }^{* * * *} P<$ 0.001. D: Weights of PDPN and CTRL MCF7 tumor xenografts at time of collection (study day 24). Lines indicate mean weights. ${ }^{* * * *} P<0.001$. 
A
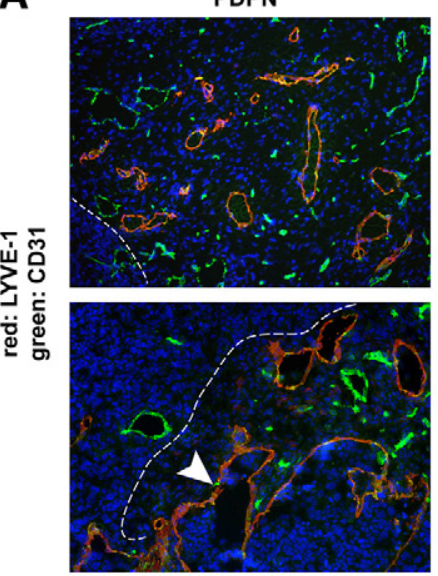

C

Primary tumor: mLYVE-1
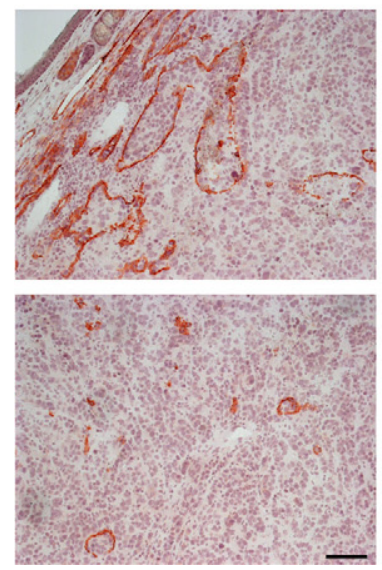

CTRL
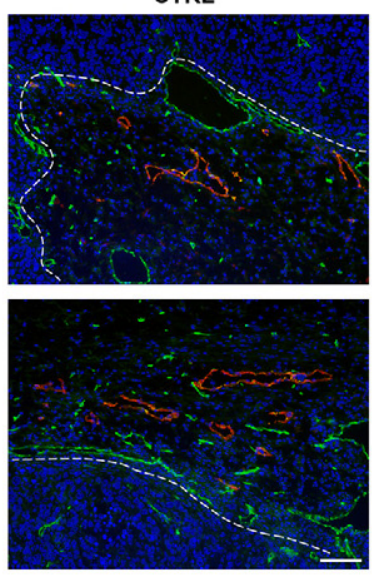

D

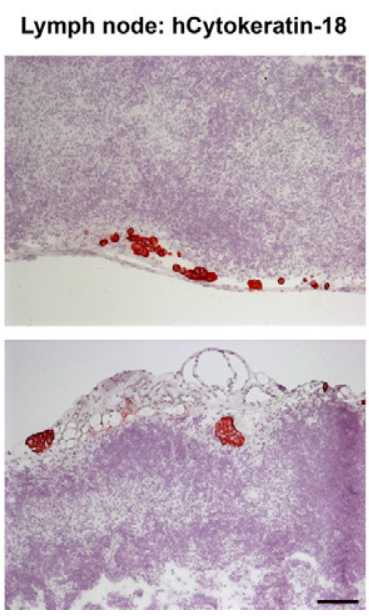

B
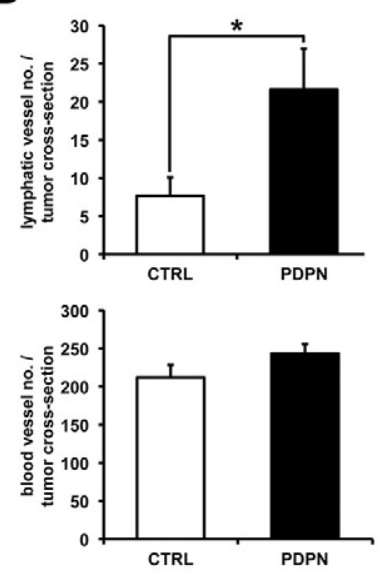

E

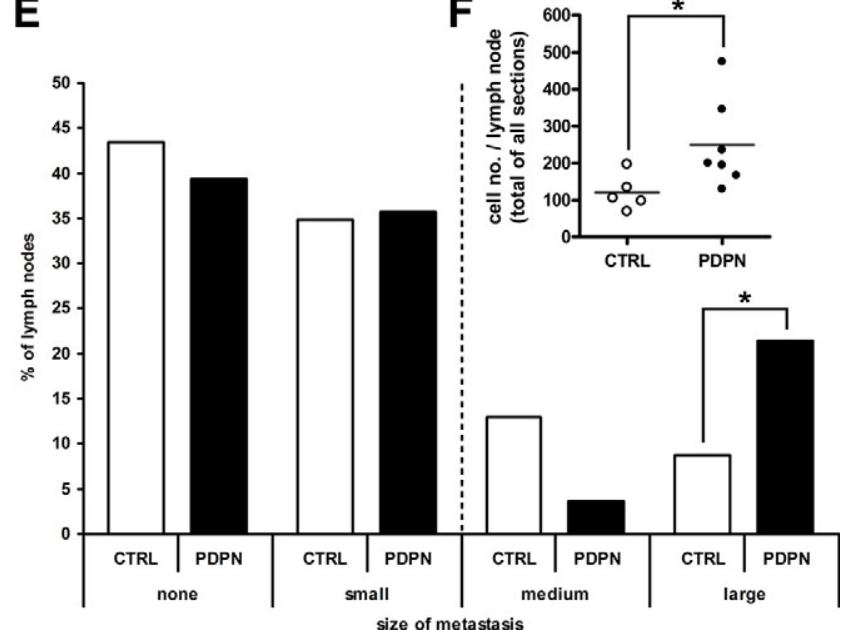

Figure 3. Podoplanin-overexpressing MCF7 breast carcinoma xenografts contain more lymphatic vessels and smaller blood vessels and form larger lymph node metastases than control tumors. A: Representative micrographs of podoplanin-overexpressing (PDPN) and control (CTRL) MCF7 tumor xenograft cross-sections, immunofluorescently stained for the lymphatic vessel marker LYVE-1 (red), the pan-vascular marker CD31 (green), and Hoechst nuclear dye (blue). Lymphatic vessels were preferentially localized near the tumor-stroma interface (dashed lines) and in PDPN tumors occasionally contained clusters of tumor cells (arrowhead). B: Quantification of lymphatic and blood vessels in PDPN and CTRL tumors. The number and size of all lymphatic vessels and of blood vessels in three hot spots in a cross-section of each tumor were determined. Data represent mean \pm SEM $\left(\mathrm{n}_{\mathrm{PDPN}}=28, \mathrm{n}_{\mathrm{CTRL}}=26\right)$. ${ }^{*} P<0.05$. C: Immunohistochemical detection of LYVE-1-positive lymphatic vessels, filled with cancer cells, in PDPN tumors. D: Immunohistochemical detection of cytokeratin-18-positive human cancer cells (dark red) in axillary lymph nodes of nude mice bearing MCF7 tumor xenografts in the mammary fat pad. E: Quantification of sentinel lymph node metastases in nude mice bearing PDPN or CTRL MCF7 tumor xenografts. Metastases were classified into small (1-20 cells), medium (20-50 cells) and large ( $>50$ cells/lymph node cross-section) metastases. Large metastases were present in 6 of 28 (PDPN) or 2 of 23 (CTRL) lymph nodes. ${ }^{*} P=0.03$. F: Total metastatic load of lymph nodes harboring medium or large metastases. The total number of cells in all cross-sections of each lymph node (cut every $100 \mu \mathrm{m})$ was counted. ${ }^{*} P=$ 0.03 . Scale bars $100 \mu \mathrm{m}$.

were evenly distributed throughout the tumors, lymphatic vessels were found in hot spots almost exclusively near the tumor-stroma interface (Figure 3A). Surprisingly, PDPN tumors contained significantly more lymphatic vessels than CTRL tumors (Figure 3, A and B). There were equal numbers of blood vessels in the two groups of tumors but their mean size was smaller in PDPN than in CTRL tumors (Figure 3B). The size of lymphatic vessels did not differ between PDPN and CTRL tumors.

Occasionally and almost exclusively in PDPN tumors, lymphatic vessels containing clusters of tumor cells were detected (Figure 3, A and C), indicating that podoplaninoverexpressing tumor cells invade the lymphatic vasculature more frequently than do control cells. Therefore, we next compared the number of metastases formed in tumor-draining, axillary lymph nodes of mice bearing PDPN or CTRL tumors. In both groups of mice approximately
$60 \%$ of draining axillary lymph nodes harbored immunohistochemically detectable tumor cells, located almost exclusively within the subcapsular lymphatic sinusesthe site where afferent lymph enters the lymph nodes (Figure 3D). Metastases were generally small, with cell numbers ranging from less than 20 to approximately 200 cells per lymph node cross-section. Quantification of tumor cells and classification of metastases into small (up to 20 cells per cross-section), medium (20-50 cells per cross-section) or large (more than 50 cells per crosssection) revealed that PDPN tumors gave rise to significantly more large metastases compared with CTRL tumors $(21.4 \%$ versus $8.7 \%, P=0.03$, binomial probability; Figure 3E). The total metastatic load of lymph nodes containing metastases classified as medium or large was estimated by counting the total number of cells observed in all of the available cross-sections of each lymph node 
A

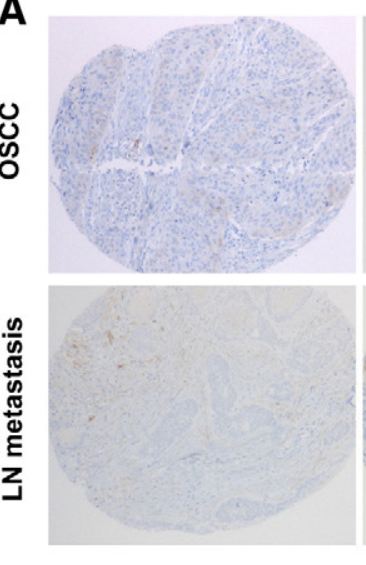



B

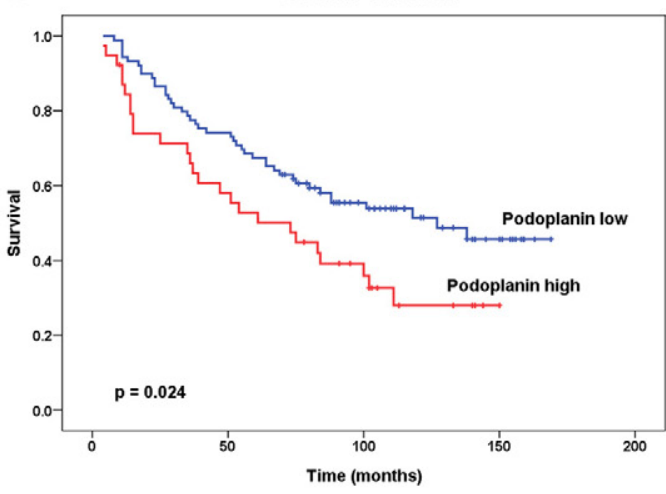

C

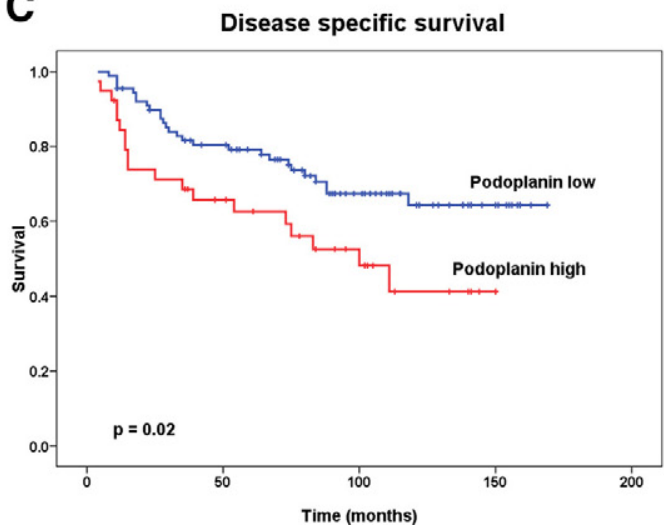

Figure 4. High levels of podoplanin expression in oral squamous cell carcinoma correlate with poor prognosis in patients. A: Immunohistochemical detection of podoplanin on a tissue microarray of human oral and oropharyngeal squamous cell carcinoma (OSCC). Representative samples with low, moderate, and high levels of podoplanin expression in primary tumors and corresponding lymph node $(\mathrm{LN})$ metastases are shown. Magnification, $\times 80$. B and $\mathbf{C}$ : Kaplan-Meier curves for overall (B) or disease-specific $(\mathbf{C})$ survival times of patients with primary OSCC that express high or low levels of podoplanin. $P=0.024(\mathbf{B})$ or $0.02(\mathbf{C}$; log rank, $n=252$ ).

(cut every $100 \mu \mathrm{m}$ ). Lymph nodes of mice bearing PDPN tumors contained significantly more tumor cells than lymph nodes of mice with CTRL tumors $(P=0.03$, MannWhitney test; Figure 3F). Taken together, these data demonstrate that cells which overexpress podoplanin have colonized the lymph nodes more readily than control cells.

\section{Podoplanin Expression Correlates with Decreased Survival Times in Patients with OSCC}

To assess the relevance of podoplanin expression by cancer cells to metastasis to lymph nodes in patients, a tissue microarray was constructed, comprising 252 samples of OSCC and 128 samples of lymph node metastases from the same patient population. Immunohistochemical analysis indicated that podoplanin expression on tumor cells was predominantly membranous and strongest at the invasive borders of primary tumors and the edges of lymph node metastases (Figure 4A). Podoplanin expression was graded using an immunoreactivity score (IRS), and tumors were categorized into podoplanin-high (IRS > 1) or podoplanin-low (IRS 0-1), according to the median IRS value of the 252 OSCCs analyzed $($ IRS $=1) .54 \%(135 / 252)$ of the primary tumors and $30.5 \%(39 / 128)$ of the lymph node metastases were classified as podoplanin-high.

Importantly, high levels of podoplanin expression correlated with a high pathological T-stage (invasion of the nearby tissue) of human OSCC ( $P=0.042$; Table 1$)$, and high podoplanin expression was associated with a pos- itive lymph node status of patients $(P=0.056$; Table 1$)$. Finally, univariate survival analysis revealed a strong correlation between a high level of podoplanin expression and decreased overall $(P=0.024$; Figure $4 \mathrm{~B})$ and disease-specific survival times $(P=0.02$; Figure $4 C)$, which in OSCC strongly depend on the lymph node status of the patient. These data reveal that podoplanin expression leads to poorer clinical outcome in patients with OSCC, by promoting lymph node metastasis.

Table 1. Correlation of Podoplanin Expression with Clinical and Pathological Parameters in Human Oral Squamous Cell Carcinoma

\begin{tabular}{cccc}
\hline Parameters & $\begin{array}{c}\text { Podoplanin } \\
\text { low; } \mathrm{n}(\%)\end{array}$ & $\begin{array}{c}\text { Podoplanin } \\
\text { high; } \mathrm{n}(\%)\end{array}$ & $\begin{array}{c}P \\
\text { value }\end{array}$ \\
\hline $\begin{array}{l}\text { Age at diagnosis } \\
\text { 555 years }\end{array}$ & $54(21)$ & $76(30)$ & 0.108 \\
$\begin{array}{l}\text { >55 years } \\
\text { Histological grade }\end{array}$ & $63(25)$ & $59(24)$ & \\
$\quad$ Well & $13(5)$ & $5(2)$ & 0.067 \\
$\quad$ Moderate & $69(27)$ & $90(36)$ & \\
Poor & $35(14)$ & $40(16)$ & \\
pT-stage & & & \\
pT1 & $34(13)$ & $31(12)$ & 0.042 \\
pT2 & $55(22)$ & $58(23)$ & \\
PT3 & $22(9)$ & $24(10)$ & \\
pT4 & $6(2)$ & $22(9)$ & \\
pN-stage & & & \\
pN0 & $50(20)$ & $42(17)$ & 0.056 \\
pN1-3 & $67(26)$ & $93(37)$ & \\
\hline
\end{tabular}


A

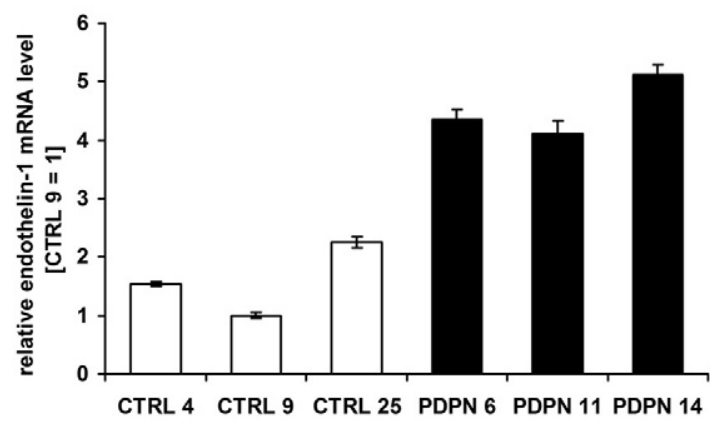

B

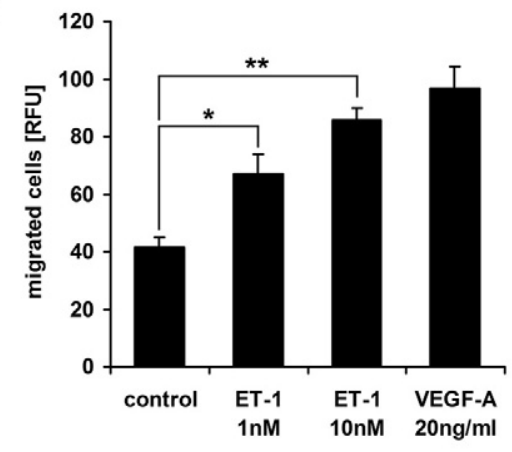

C

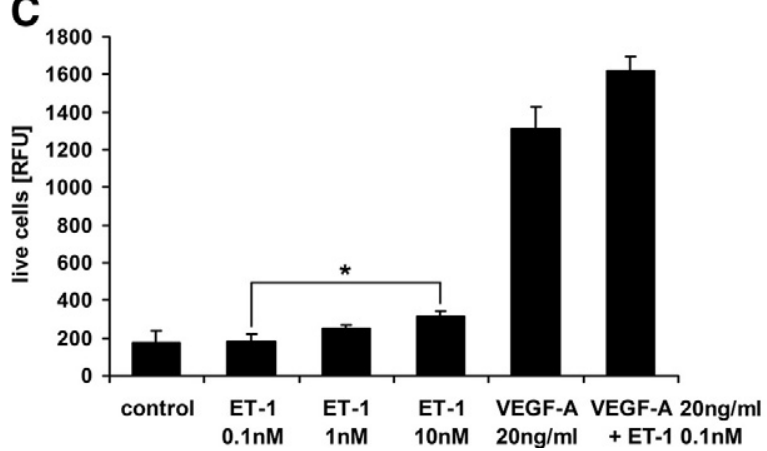

D

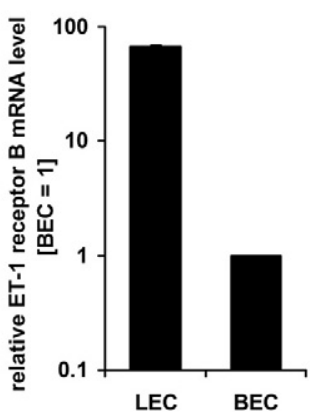

E

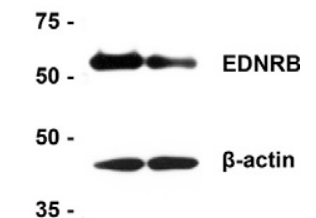

[kDa] LEC BEC

Figure 5. Expression of endothelin-1 (ET-1) is up-regulated in podoplanin-overexpressing MCF7 breast carcinoma xenografts and ET-1 promotes migration and proliferation of lymphatic endothelial cells expressing endothelin receptor B. A: Relative human ET-1 mRNA levels, measured by real-time RT-PCR in MCF7 tumors derived from podoplanin-overexpressing (PDPN) or control (CTRL) cell clones. Data represent mean \pm SD ( $n=3$ ), with the value for clone CTRL 9 set to 1 . B: Migration of primary human lymphatic endothelial cells in the presence of 1 or $10 \mathrm{nmol} / \mathrm{L}$ recombinant human ET- 1 or $20 \mathrm{ng} / \mathrm{ml}$ human VEGF-A in a two-chamber migration assay for 4 hours at $37^{\circ} \mathrm{C}$. Data represent mean fluorescence from calcein-stained transmigrated cells \pm SEM $(n=3)$. ${ }^{* *} P=0.001,{ }^{*} P=0.025$. C: Proliferation of lymphatic endothelial cells in the presence of different concentrations of ET-1 and/or VEGF-A for 48 hours. Data represent mean fluorescence from 4-methylumbelliferyl heptanoate-stained live cells $\pm \operatorname{SEM}(n=3) .{ }^{*} P=0.05$. D: Relative endothelin receptor B (ENDRB) mRNA levels, measured by real-time RT-PCR in primary human lymphatic (LECs) and blood vascular endothelial cells (BECs). Data are represented as mean $+/-$ SD $(n=3)$, with the value for BEC set to 1. E: Immunoblot detection of ENDRB, immunoprecipitated from lysates of primary human LECs and BECs ( $500 \mu \mathrm{g}$ of total protein). $\beta$-actin served as control for equal loading.

\section{Podoplanin Up-Regulates the Expression of Endothelin-1 in Vivo}

To elucidate the molecular mechanisms by which podoplanin promotes lymphangiogenesis and tumor cell dissemination, we compared the transcriptional profiles of PDPN and CTRL MCF7 breast carcinoma xenografts. RNA samples of all tumors $(n=8-10)$ derived from the same cell clone were pooled for microarray analysis and each sample was applied to both human and mouse microarrays. In both types of microarrays, samples of the same group (ie, PDPN or CTRL) clustered together (see Supplemental Figure S2 at http://ajp.amjpathol.org), indicating that consistent differences existed between, but not within the two groups.

Among the genes that were up-regulated by twofold or more in PDPN tumors with a $P$ value of less than 0.05 $(0.64 \%$ in the human arrays, $2.67 \%$ in the mouse arrays $)$ we searched for potential mediators of the increased lymphangiogenesis observed in these tumors. Although VEGF-C, a potent lymphangiogenic factor, was among the up-regulated genes in the human microarray (see Supplemental Table S1 at http://ajp.amjpathol.org), a consistent increase of VEGF-C mRNA levels in PDPN tumors could not be confirmed by real-time RT-PCR (see Supplemental Figure S3A at http://ajp.amjpathol.org). Furthermore, using an antibody array, we did not detect differences in the protein levels of other known lymphangiogenic growth factors (see Supplemental Figure S3B at $h$ ttp://ajp.amjpathol.org). The extent of immune cell infiltration, a possible source of growth factors, was comparable in all tumors (Supplemental Figure S1 at $h t t p: / /$ ajp.amjpathol.org) and the mouse microarray revealed that none of the known lymphangiogenic factors was differentially expressed in the murine stroma of PDPN versus CTRL tumors (see Supplemental Table S2 at http://ajp.amjpathol.org).

Using real-time RT-PCR we found, however, that the expression of human endothelin-1 (ET-1) mRNA was up to fivefold higher in PDPN than in CTRL tumors, in agreement with the corresponding microarray result (Figure 5A and Supplemental Table S1 at http://ajp.amjpathol.org). Accordingly, several genes involved in endothelin signaling were up-regulated in the murine stroma of PDPN tumors (Adcy5, Akt3, Ptgs2, Pla2g4a; Supplemental Table T2 at http://ajp.amjpathol.org), while tumor cells up-regulated matrix metalloproteinase 2, which is induced by ET-1. ${ }^{28,29}$ Given that ET-1 is a potent vasoconstrictor peptide, ${ }^{30}$ the up-regulation of numerous mouse genes associated with muscle contraction (Supplemental Table S2 at $h$ ttp://ajp.amjpathol.org), along with the reduced size of blood vessels (Figure 3B), might result from endothelin's action on vascular smooth muscle cells in the stroma of PDPN tumors. 


\section{Endothelin-1 Induces Lymphangiogenesis in Vivo}

Because ET-1 induces an angiogenic phenotype in blood vascular endothelial cells (BECs) and modulates tumor angiogenesis in breast and other human cancers, ${ }^{28,31}$ we investigated whether it might also act as an inducer of lymphangiogenesis. Indeed, recombinant human ET-1 promoted the migration of primary human lymphatic endothelial cells (LECs) in a dose-dependent manner (Figure 5B). Also, a moderate, dose-dependent induction of LEC proliferation was observed after exposure to ET-1 (10 nmol/L versus $0.1 \mathrm{nmol} / \mathrm{L}$ ET- $1, P=0.05$; Figure $5 \mathrm{C}$ ). Interestingly, although $0.1 \mathrm{nmol} / \mathrm{L}$ ET-1 alone did not affect LEC proliferation, when administered in combination with VEGF-A $(20 \mathrm{ng} / \mathrm{ml})$ it induced a greater degree of LEC proliferation than VEGF-A alone $(P=0.08)$, indicating that these two factors act synergistically. Furthermore, we found endothelin receptor B mRNA and protein to be more abundantly expressed by LECs than by BECs (Figure 5, D and E), whereas expression of endothelin receptor A could be detected exclusively in BECs (see Supplemental Figure S4 at http://ajp.amjpathol.org).

Importantly, by means of a Matrigel plug assay, we could show that ET-1 also promotes lymphangiogenesis in vivo. Two weeks after placement of the Matrigel plug, the number of lymphatic vessels in the skin overlying the plug was significantly increased if the plug contained ET-1 rather than PBS as vehicle control $(P=0.005$; Figure 6, $\mathrm{A}$ and $\mathrm{C}$ ). The number of blood vessels, on the other hand, was not altered by ET-1 in this assay (Figure 6 , B and C). Interestingly, these effects of ET-1-promotion of lymph- but not (hem)angiogenesis-are identical to the effects of podoplanin overexpression in MCF7 tumor xenografts.

Taken together, these results suggest that podoplanininduced tumor lymphangiogenesis might be mediated by up-regulation of ET-1, which acts on the lymphatic endothelium through endothelin receptor $\mathrm{B}$.

\section{Podoplanin Promotes the in Vivo Expression of Cytoskeletal and Extracellular Matrix Molecules, Including Tenascin-C and Villin-1}

Both comparisons of the sets of human and mouse genes that were up-regulated in PDPN tumors to the respective whole genome microarray reference lists revealed a significant overrepresentation of genes that encode cytoskeletal and extracellular matrix proteins (Table 2). Among the latter, tenascin- $\mathrm{C}$ is of particular interest with regard to malignancy, as it is highly expressed in many cancerous tissues and has multiple effects on cell behavior (reviewed in 32). Tenascin- $C$ was the most significantly up-regulated gene in the mouse microarrays $(P=$ $1.83 \times 10^{-5}$; Supplemental Table S2 at http://ajp.amjpathol.org). Real-time RT-PCR and immunohistochemical analyses revealed tenascin- $C$ mRNA and protein to be more abundant in the stroma of PDPN tumors compared with CTRL tumors (Figure 7, A and B). Although in-
A

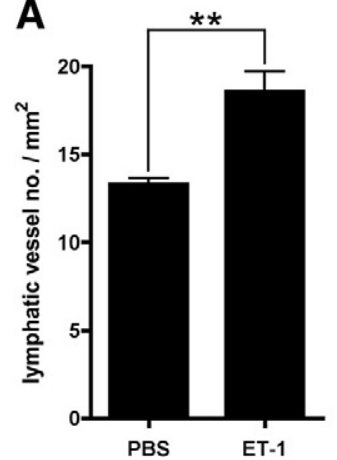

B

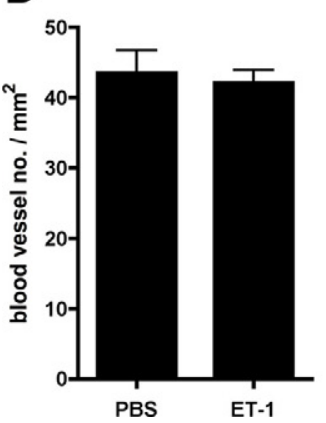

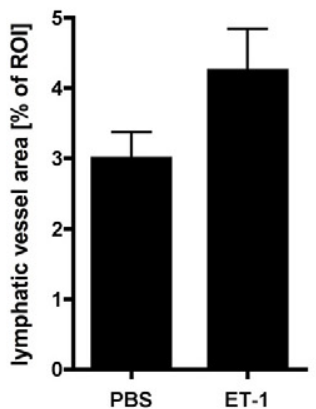

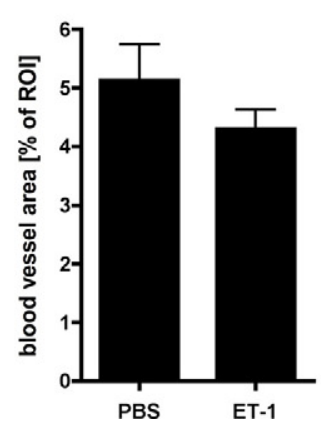

C
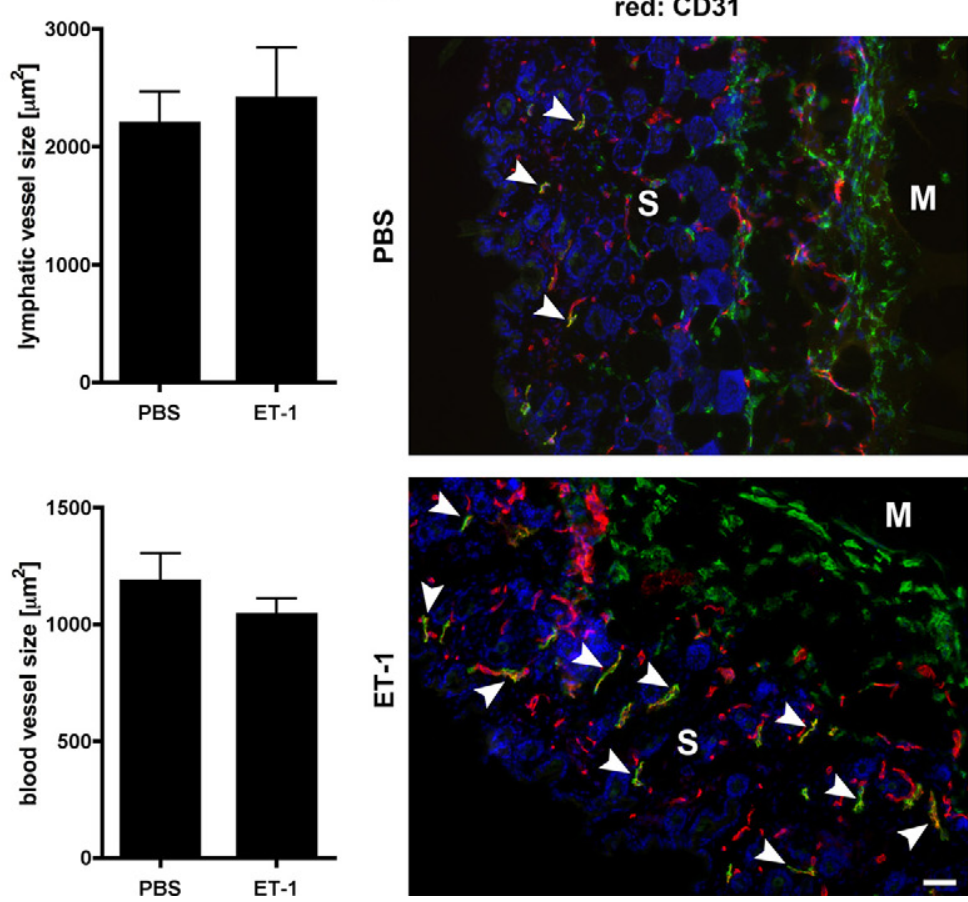

Figure 6. Endothelin-1 (ET-1) promotes lymphangiogenesis in vivo. Number, relative area, and size of lymphatic vessels (A) or blood vessels (B) in mouse skin overlying Matrigel plugs containing $1 \mu \mathrm{mol} / \mathrm{L}$ human ET- 1 or PBS as vehicle control, two weeks after application of the plugs. Data represent mean \pm SEM $(n=$ 4). ${ }^{* *} P=0.005$. C: Representative micrographs of skin cross-sections from Matrigel plug assay, immunofluorescently stained for the lymphatic vessel marker LYVE-1 (green), the pan-vascular marker CD31 (red), and Hoechst nuclear dye (blue). Lymphatic vessels (yellow; CD31+/LYVE-1+) are indicated by white arrowheads. Single green cells represent CD31-/LYVE-1+ macrophages surrounding the Matrigel. S indicates skin; M, Matrigel plug. Scale bar $=100 \mu \mathrm{m}$. 
Table 2. Significantly Enriched Molecular Functions in Sets of Genes That Are Up-Regulated in Human Tumor Cells or Murine Stromal Cells of Podoplanin-Overexpressing MCF7 Breast Carcinoma Xenografts $(P<0.05)$

\begin{tabular}{|c|c|c|c|c|}
\hline Molecular function & Expected no. of genes in set & Actual no. of genes in set & Fold-enrichment & $P$ value* \\
\hline \multicolumn{5}{|l|}{ Human genes } \\
\hline Extracellular matrix & 1.60 & 12 & 7.5 & $2.6 \times 10^{-6}$ \\
\hline Actin binding cytoskeletal protein & 1.70 & 11 & 6.5 & $2.0 \times 10^{-4}$ \\
\hline Cytoskeletal protein & 3.88 & 13 & 3.4 & 0.0042 \\
\hline \multicolumn{5}{|l|}{ Mouse genes } \\
\hline Actin binding cytoskeletal protein & 4.29 & 16 & 3.7 & 0.0015 \\
\hline Extracellular matrix & 4.43 & 14 & 3.2 & 0.0055 \\
\hline
\end{tabular}

${ }^{*}$ Calculated using the Bonferroni correction for multiple testing.

creased tenascin-C mRNA levels in PDPN tumors were also detected using the human microarrays (Supplemental Table S1 at http://ajp.amjpathol.org), neither RT-PCR (using primers specific for the human transcript) nor immunohistochemistry (with an antibody specific for the human protein) revealed any significant expression of tenascin-C by the tumor cells themselves (not shown).

An interesting cytoskeletal protein that was up-regulated in PDPN tumors was villin-1, an exceptionally versatile epithelial cell-specific actin-binding protein (reviewed in 33). We confirmed the induction of human villin-1 expression in PDPN tumors at the mRNA and protein level (Figure 7, C and D). Immunohistochemical analysis unexpectedly revealed that villin-1 expression was not uniform throughout the tumor but restricted to single tumor cells or small clusters of tumor cells predominantly located near highly vascularized stromal compartments, where tumor cells might invade host tissue and vessels (Figure 7E). Collectively, these results reveal that expression of podoplanin on the surface of tumor cells induces changes of the tumor cell cytoskeleton as well as the surrounding extracellular matrix, which could increase the motility of tumor cells and thus promote their dissemination.

\section{Discussion}

Metastasis of many human cancers, including breast cancer and head and neck squamous cell carcinoma, occurs primarily through the lymphatic system, and the extent of lymph node involvement often determines the patients' prognosis. In this study, we found that expression of the membrane glycoprotein podoplanin on cancer cells increased lymph node metastasis in a human breast carcinoma xenograft model as well as in a large cohort of patients with OSCC. Importantly, we also found that high levels of podoplanin expression in tumors reduced overall and disease-specific survival times of patients with OSCC, which is in line with the presence of lymph node
A

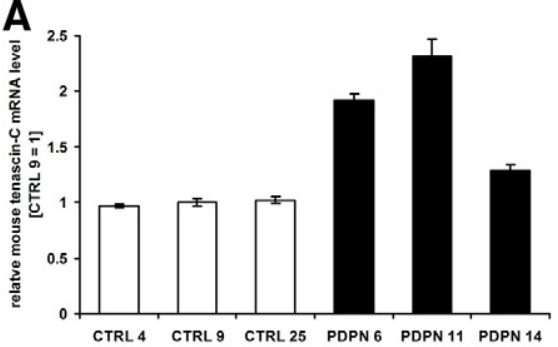

C



E

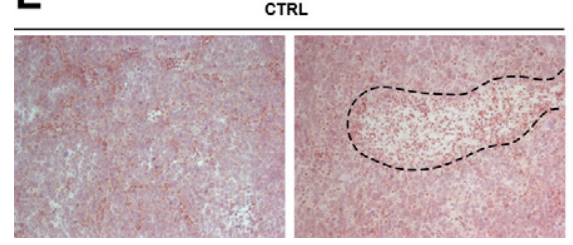

B

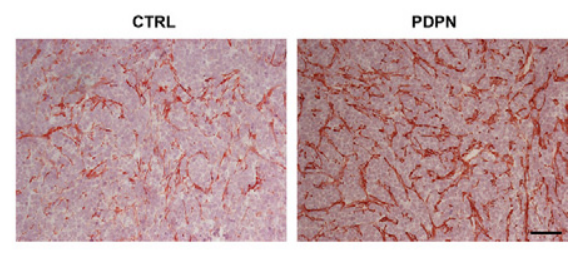

D
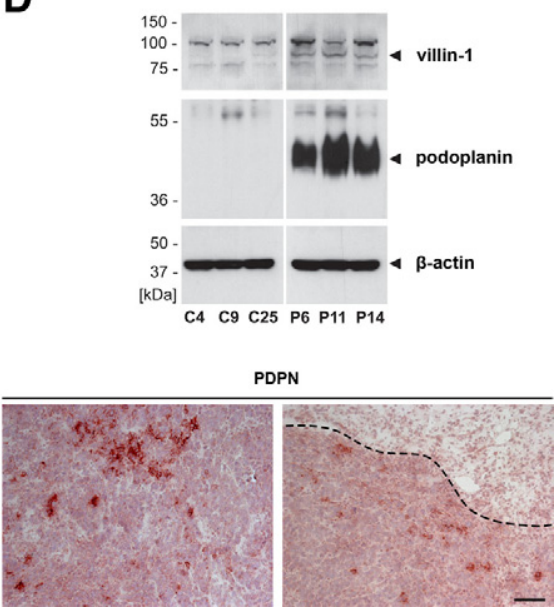

Figure 7. mRNA and protein levels of tenascin-C and villin-1 are increased in MCF7 breast carcinoma xenografts that overexpress podoplanin, compared with control tumors. A: Relative mouse tenascin-C mRNA levels, measured by real-time RT-PCR in MCF7 tumors derived from podoplanin-overexpressing (PDPN) or control (CTRL) cell clones. Data are represented as mean $\pm \mathrm{SD}(n=3)$, with the value for clone CTRL 9 set to 1. B: Immunohistochemical detection of tenascin-C in cross-sections of PDPN and CTRL MCF7 tumor xenografts. C: Relative human villin-1 mRNA levels, measured by real-time RTPCR as in A. D: Immunoblot detection of human villin-1 and human podoplanin in lysates of PDPN and CTRL MCF7 tumors. $180 \mu \mathrm{g}$ (top) or $30 \mu \mathrm{g}$ (middle and bottom) total protein were used for each sample and $\beta$-actin served as control for equal loading. E: Immunohistochemical detection of human villin-1 in cross-sections of PDPN and CTRL MCF7 tumor xenografts, with villin-1-positive tumor cells preferentially located near tumor stroma interfaces (dashed lines). Scale bars $=100 \mu \mathrm{m}$. 
metastasis_beside distant metastasis_being the single most adverse independent prognostic factor in patients with squamous cell carcinomas of the head and neck region. ${ }^{34}$ These clinical findings are supported by several recent studies, which-although in much smaller patient cohorts - similarly report an association between podoplanin expression, lymph node metastasis, and/or poor clinical outcome in various types of OSCC. ${ }^{35-38}$

Our data reveal that podoplanin promotes metastasis to lymph nodes by affecting several steps of cancer progression-importantly without promoting primary tumor growth. Podoplanin expression renders cancer cells more motile, thereby facilitating the local invasion of host tissue, as reflected by the advanced pathological T-stage of human OSCC with high levels of podoplanin expression. Unexpectedly, microarray analyses indicated that molecules within tumor cells themselves as well as in the tumor stroma mediate these effects of podoplanin. Among other potentially interesting mediators, we found villin-1 and tenascin-C to be significantly up-regulated in PDPN tumors. Interestingly, villin-1 shares considerable structural and functional features with ezrin (also referred to as villin-2), which interacts with podoplanin. ${ }^{18}$ Both ezrin and villin-1 are actin- and phospholipid-binding cytoskeletal proteins that are located in the microvillar compartment of epithelial cells and essential for microvillus assembly (reviewed in 32, 39). Similar to what has been reported for podoplanin, overexpression of villin-1 results in the loss of stress fibers, the formation of microvilli-like structures, and increased motility of diverse cell types. ${ }^{40-42}$ Thus, it is conceivable that villin-1 complements, or under certain circumstances even replaces, ezrin in mediating podoplanin-induced cytoskeletal reorganization and cell motility.

Unlike villin-1, tenascin-C was expressed in the stroma of PDPN tumors. The effects of tenascin- $C$ in tumor tissues are diverse and appear to be highly context- and cell type-specific. There is, however, convincing evidence from studies of different types of cancer that tenascin-C supports epithelial-mesenchymal transition as well as tumor cell migration and invasion-events that lead to metastasis (reviewed in 32). Indeed, high levels of tenascin-C expression, especially at the invasive tumor front, correlate with metastasis to lymph nodes and poor prognosis in patients with different types of cancer, ${ }^{43-46}$ similar to what we observed for podoplanin in OSCC.

Our findings show that podoplanin expression induces complex changes of the tumor microenvironment which collectively promote tumor cell motility, invasion, and metastasis. The most surprising finding of this study, however, was that ectopic expression of podoplanin promoted lymphangiogenesis in breast carcinoma xenografts, which together with the increased invasion of tumor stroma and vessels localized there, would potentiate the prometastatic effects of podoplanin. We previously reported that overexpression of VEGF-C increases lymphatic metastasis by inducing tumor lymphangiogenesis without promoting primary tumor growth. ${ }^{47}$ Rather than any known lymphangiogenic growth factor, however, we found increased expression of ET-1 in podoplanin-overexpressing tumor xenografts. In agreement with a recent report, ${ }^{48}$ we identified $\mathrm{ET}-1$ as a novel promotor of lymphangiogenesis in vitro and in vivo which most likely acts through ENDRB, the receptor subtype predominantly expressed on endothelial cells. ${ }^{49}$ The increased expression level of ENDRB in LECs compared with BECs indicates that the lymphatic endothelium might be more sensitive to ET-1 than blood vascular endothelium and might explain the fact that only lymphangiogenesis but not angiogenesis was induced in PDPN tumor xenografts, as well as in skin overlying ET-1-containing Matrigel plugs. Beside its role in lymphangiogenesis, ET-1 could also contribute to cancer cell motility and invasiveness through induction of tumor proteinases. ${ }^{29,50,51}$ We observed up-regulation of matrix metalloproteinase 2 in PDPN tumor xenografts, which might be induced in an autocrine manner via ENDRA expressed on tumor cells. Remarkably, increased serum levels of ET-1 have been observed in breast cancer patients with lymph node metastases compared with patients without lymph node involvement, ${ }^{51}$ supporting its role in lymphatic metastasis.

The exact mechanism by which podoplanin induces changes in gene expression remains to be elucidated. They might be mediated through RhoA, which is known to be involved in signaling pathways leading to transcriptional control, ${ }^{52-54}$ and the activity of which we and others found to be modulated by podoplanin. ${ }^{17,18}$ In addition, signals from the tumor stroma appear to contribute to the gene expression changes in PDPN tumors, as they were not observed in podoplanin-overexpressing cells in vitro (not shown). Such additional stimuli may include paracrine growth factors, cytokines, components of the extracellular matrix, hypoxia, reactive oxygen species, metabolites, or mechanical force, to name just a few. Gene expression changes resulting from the interaction of different cell types are well known, eg, from would-healing processes, or from simple co-culture experiments, in which - interestingly - the expression of both endothelin-1 and tenascin-C was reported to be altered. ${ }^{55}$ Thus, the gene expression changes observed in podoplaninoverexpressing tumors very likely depend on the presence of podoplanin in conjunction with additional stimuli from the tumor stroma.

Altogether, our findings identify a novel mechanism of lymphatic cancer metastasis that is mediated by cancer cell-expressed podoplanin, which promotes tumor cell motility and tumor lymphangiogenesis, but not primary tumor growth. Interference with podoplanin function could therefore represent a novel therapeutic strategy to combat advanced cancer.

\section{Acknowledgments}

We thank Dr. Sam W. Lee for the MCF7 tet-off cells, Dr. Dario Neri for the anti-tenascin-C antibody, and Dr. Nadja Bänziger-Tobler, Dr. Viviane Mumprecht, Benjamin Vigl, Dr. Daniela Marino, Silvana Zgraggen, Jana Zielinski, and Martina Storz for help with animal procedures, histology, and tissue microarray construction. 


\section{References}

1. Breiteneder-Geleff $S$, Matsui K, Soleiman A, Meraner P, Poczewski $H$, Kalt R, Schaffner G, Kerjaschki D: Podoplanin, novel 43-kd membrane protein of glomerular epithelial cells, is down-regulated in puromycin nephrosis. Am J Pathol 1997, 151:1141-1152

2. Zimmer G, Oeffner F, Von Messling V, Tschernig T, Groness HJ, Klenk HD, Herrler G: Cloning and characterization of gp36, a human mucintype glycoprotein preferentially expressed in vascular endothelium. Biochem J 1999, 341:277-284

3. Breiteneder-Geleff S, Soleiman A, Kowalski H, Horvat R, Amann G, Kriehuber E, Diem K, Weninger W, Tschachler E, Alitalo K, Kerjaschki $D$ : Angiosarcomas express mixed endothelial phenotypes of blood and lymphatic capillaries: podoplanin as a specific marker for lymphatic endothelium. Am J Pathol 1999, 154:385-394

4. Schacht V, Ramirez MI, Hong YK, Hirakawa S, Feng D, Harvey N, Williams M, Dvorak AM, Dvorak HF, Oliver G, Detmar M: T1alpha/ podoplanin deficiency disrupts normal lymphatic vasculature formation and causes lymphedema. EMBO J 2003, 22:3546-3556

5. Ramirez MI, Millien G, Hinds A, Cao Y, Seldin DC, Williams MC: T1alpha, a lung type I cell differentiation gene, is required for normal lung cell proliferation and alveolus formation at birth. Dev Biol 2003, 256:61-72

6. Gandarillas A, Scholl FG, Benito N, Gamallo C, Quintanilla M: Induction of PA2.26, a cell-surface antigen expressed by active fibroblasts, in mouse epidermal keratinocytes during carcinogenesis. Mol Carcinog 1997, 20:10-18

7. Schacht V, Dadras SS, Johnson LA, Jackson DG, Hong YK, Detmar M: Up-regulation of the lymphatic marker podoplanin, a mucin-type transmembrane glycoprotein, in human squamous cell carcinomas and germ cell tumors. Am J Pathol 2005, 166:913-921

8. Kato Y, Kaneko M, Sata M, Fujita N, Tsuruo T, Osawa M: Enhanced expression of aggrus (T1alpha/podoplanin), a platelet-aggregationinducing factor in lung squamous cell carcinoma. Tumour Biol 2005, 26:195-200

9. Martin-Villar E, Scholl FG, Gamallo C, Yurrita MM, Munoz-Guerra M, Cruces J, Quintanilla M: Characterization of human PA2.26 antigen (T1alpha-2, podoplanin), a small membrane mucin induced in oral squamous cell carcinomas. Int J Cancer 2005, 113:899-910

10. Kimura N, Kimura I: Podoplanin as a marker for mesothelioma. Pathol Int 2005, 55:83-86

11. Shibahara J, Kashima T, Kikuchi Y, Kunita A, Fukayama M: Podoplanin is expressed in subsets of tumors of the central nervous system. Virchows Arch 2006, 448:493-499

12. Watanabe M, Okochi E, Sugimoto $\mathrm{Y}$, Tsuruo $\mathrm{T}$ : Identification of a platelet-aggregating factor of murine colon adenocarcinoma 26: Mr 44,000 membrane protein as determined by monoclonal antibodies. Cancer Res 1988, 48:6411-6416

13. Watanabe M, Sugimoto $Y$, Tsuruo T: Expression of a Mr 41,000 glycoprotein associated with thrombin-independent platelet aggregation in high metastatic variants of murine B16 melanoma. Cancer Res 1990, 50:6657-6662

14. Mishima K, Kato Y, Kaneko MK, Nishikawa R, Hirose T, Matsutani M: Increased expression of podoplanin in malignant astrocytic tumors as a novel molecular marker of malignant progression. Acta Neuropathol 2006, 111:483-488

15. Raica M, Ribatti D, Mogoanta L, Cimpean AM, Ioanovici S: Podoplanin expression in advanced-stage gastric carcinoma and prognostic value of lymphatic microvessel density. Neoplasma 2008, 55:455-460

16. Scholl FG, Gamallo C, Vilaro S, Quintanilla M: Identification of PA2.26 antigen as a novel cell-surface mucin-type glycoprotein that induces plasma membrane extensions and increased motility in keratinocytes. J Cell Sci 1999, 112:4601-4613

17. Wicki A, Lehembre F, Wick N, Hantusch B, Kerjaschki D, Christofori G: Tumor invasion in the absence of epithelial-mesenchymal transition: podoplanin-mediated remodeling of the actin cytoskeleton. Cancer Cell 2006, 9:261-272

18. Martin-Villar E, Megias D, Castel S, Yurrita MM, Vilaro S, Quintanilla M: Podoplanin binds ERM proteins to activate RhoA and promote epithelial-mesenchymal transition. J Cell Sci 2006, 119:4541-4553

19. Scholl FG, Gamallo C, Quintanilla M: Ectopic expression of PA2.26 antigen in epidermal keratinocytes leads to destabilization of adherens junctions and malignant progression. Lab Invest 2000, 80:1749-1759
20. Kato Y, Fujita N, Kunita A, Sato S, Kaneko M, Osawa M, Tsuruo T: Molecular identification of Aggrus/T1alpha as a platelet aggregationinducing factor expressed in colorectal tumors. J Biol Chem 2003, 278:51599-51605

21. Kunita A, Kashima TG, Morishita Y, Fukayama M, Kato Y, Tsuruo T, Fujita N: The platelet aggregation-inducing factor aggrus/podoplanin promotes pulmonary metastasis. Am J Pathol 2007, 170:1337-1347

22. Shin JW, Huggenberger R, Detmar M: Transcriptional profiling of VEGF-A and VEGF-C target genes in lymphatic endothelium reveals endothelial-specific molecule-1 as a novel mediator of lymphangiogenesis. Blood 2008, 112:2318-2326

23. Kajiya K, Hirakawa S, Ma B, Drinnenberg I, Detmar M: Hepatocyte growth factor promotes lymphatic vessel formation and function. EMBO J 2005, 24:2885-2895

24. Brack SS, Silacci M, Birchler M, Neri D: Tumor-targeting properties of novel antibodies specific to the large isoform of tenascin-C. Clin Cancer Res 2006, 12:3200-3208

25. Kononen J, Bubendorf L, Kallioniemi A, Barlund M, Schraml P, Leighton S, Torhorst J, Mihatsch MJ, Sauter G, Kallioniemi OP: Tissue microarrays for high-throughput molecular profiling of tumor specimens. Nat Med 1998, 4:844-847

26. Albinger-Hegyi A, Stoeckli SJ, Schmid S, Storz M, lotzova G, ProbstHensch NM, Rehrauer H, Tinguely M, Moch H, Hegyi I: Lysyl oxidase expression is an independent marker of prognosis and a predictor of lymph node metastasis in oral and oropharyngeal squamous cell carcinoma (OSCC). Int J Cancer 2010, 126:2653-2662

27. Thomas PD, Campbell MJ, Kejariwal A, Mi H, Karlak B, Daverman R, Diemer K, Muruganujan A, Narechania A: PANTHER: a library of protein families and subfamilies indexed by function. Genome Res 2003, 13:2129-2141

28. Salani D, Taraboletti G, Rosano L, Di Castro V, Borsotti P, Giavazzi R, Bagnato A: Endothelin-1 induces an angiogenic phenotype in cultured endothelial cells and stimulates neovascularization in vivo. Am J Pathol 2000, 157:1703-1711

29. Rosano L, Varmi M, Salani D, Di Castro V, Spinella F, Natali PG, Bagnato A: Endothelin-1 induces tumor proteinase activation and invasiveness of ovarian carcinoma cells. Cancer Res 2001, 61:8340-8346

30. Yanagisawa M, Kurihara H, Kimura S, Tomobe Y, Kobayashi M, Mitsui Y, Yazaki Y, Goto K, Masaki T: A novel potent vasoconstrictor peptide produced by vascular endothelial cells. Nature 1988, 332:411-415

31. Wulfing P, Kersting C, Tio J, Fischer RJ, Wulfing C, Poremba C, Diallo R, Bocker W, Kiesel L: Endothelin-1-, endothelin-A-, and endothelinB-receptor expression is correlated with vascular endothelial growth factor expression and angiogenesis in breast cancer. Clin Cancer Res 2004, 10:2393-2400

32. Orend G, Chiquet-Ehrismann R: Tenascin-C induced signaling in cancer. Cancer Lett 2006, 244:143-163

33. Khurana S, George SP: Regulation of cell structure and function by actin-binding proteins: villin's perspective. FEBS Lett 2008, 582: $2128-2139$

34. Ferlito A, Rinaldo A, Robbins KT, Leemans CR, Shah JP, Shaha AR, Andersen PE, Kowalski LP, Pellitteri PK, Clayman GL, Rogers SN, Medina JE, Byers RM: Changing concepts in the surgical management of the cervical node metastasis. Oral Oncol 2003, 39:429-435

35. Chuang WY, Yeh CJ, Wu YC, Chao YK, Liu YH, Tseng CK, Chang HK, Liu HP, Hsueh C: Tumor cell expression of podoplanin correlates with nodal metastasis in esophageal squamous cell carcinoma. Histol Histopathol 2009, 24:1021-1027

36. Kawaguchi H, El-Naggar AK, Papadimitrakopoulou V, Ren H, Fan YH, Feng L, Lee JJ, Kim E, Hong WK, Lippman SM, Mao L: Podoplanin: a novel marker for oral cancer risk in patients with oral premalignancy. J Clin Oncol 2008, 26:354-360

37. Rahadiani N, Ikeda Jl, Makino T, Tian T, Qiu Y, Mamat S, Wang Y, Dok $\mathrm{Y}$, Aozasa $\mathrm{K}$, Morii E: Tumorigenic role of podoplanin in esophageal squamous-cell carcinoma. Ann Surg Oncol 2010, 17:1311-1323

38. Yuan P, Temam S, El-Naggar A, Zhou X, Liu DD, Lee JJ, Mao L: Overexpression of podoplanin in oral cancer and its association with poor clinical outcome. Cancer 2006, 107:563-569

39. Louvet-Vallee S: ERM proteins: from cellular architecture to cell signaling. Biol Cell 2000, 92:305-316

40. Friederich E, Huet C, Arpin M, Louvard D: Villin induces microvilli growth and actin redistribution in transfected fibroblasts. Cell 1989, 59:461-475

41. Tomar A, Wang Y, Kumar N, George S, Ceacareanu B, Hassid A, 
Chapman KE, Aryal AM, Waters CM, Khurana S: Regulation of cell motility by tyrosine phosphorylated villin. Mol Biol Cell 2004, $15: 4807-4817$

42. Wang Y, Tomar A, George SP, Khurana S: Obligatory role for phospholipase C-gamma(1) in villin-induced epithelial cell migration. Am J Physiol Cell Physiol 2007, 292:C1775-C1786

43. Ioachim E, Charchanti A, Briasoulis E, Karavasilis V, Tsanou H, Arvanitis DL, Agnantis NJ, Pavlidis N: Immunohistochemical expression of extracellular matrix components tenascin, fibronectin, collagen type IV and laminin in breast cancer: their prognostic value and role in tumour invasion and progression. Eur J Cancer 2002, 38:2362-2370

44. Ishihara A, Yoshida T, Tamaki H, Sakakura T: Tenascin expression in cancer cells and stroma of human breast cancer and its prognostic significance. Clin Cancer Res 1995, 1:1035-1041

45. Emoto K, Yamada Y, Sawada H, Fujimoto H, Ueno M, Takayama T, Kamada K, Naito A, Hirao S, Nakajima Y: Annexin II overexpression correlates with stromal tenascin-C overexpression: a prognostic marker in colorectal carcinoma. Cancer 2001, 92:1419-1426

46. Juhasz A, Bardos H, Repassy G, Adany R: Characteristic distribution patterns of tenascin in laryngeal and hypopharyngeal cancers. Laryngoscope 2000, 110:84-92

47. Hirakawa S, Brown LF, Kodama S, Paavonen K, Alitalo K, Detmar M: VEGF-C-induced lymphangiogenesis in sentinel lymph nodes promotes tumor metastasis to distant sites. Blood 2007, 109:1010-1017

48. Spinella F, Garrafa E, Di Castro V, Rosano L, Nicotra MR, Caruso A, Natali PG, Bagnato A: Endothelin-1 stimulates Iymphatic endothelial cells and lymphatic vessels to grow and invade. Cancer Res 2009, 69:2669-2676

49. Sakurai T, Yanagisawa M, Takuwa Y, Miyazaki H, Kimura S, Goto K Masaki T: Cloning of a cDNA encoding a non-isopeptide-selective subtype of the endothelin receptor. Nature 1990, 348:732-735

50. Grimshaw MJ, Hagemann T, Ayhan A, Gillett CE, Binder C, Balkwill FR: A role for endothelin-2 and its receptors in breast tumor cell invasion. Cancer Res 2004, 64:2461-2468

51. Hagemann T, Binder C, Binder L, Pukrop T, Trumper L, Grimshaw MJ: Expression of endothelins and their receptors promotes an invasive phenotype of breast tumor cells but is insufficient to induce invasion in benign cells. DNA Cell Biol 2005, 24:766-776

52. Hill CS, Wynne J, Treisman R: The Rho family GTPases RhoA. Rac1, and CDC42Hs regulate transcriptional activation by SRF. Cell 1995, 81:1159-1170

53. Marinissen MJ, Chiariello M, Tanos T, Bernard O, Narumiya S, Gutkind JS: The small GTP-binding protein RhoA regulates c-jun by a ROCK-JNK signaling axis. Mol Cell 2004, 14:29-41

54. Perona R, Montaner S, Saniger L, Sanchez-Perez I, Bravo R, Lacal JC: Activation of the nuclear factor-kappaB by Rho, CDC42, and Rac-1 proteins Genes Dev 1997, 11:463-475

55. Shephard P, Martin G, Smola-Hess S, Brunner G, Krieg T, Smola H: Myofibroblast differentiation is induced in keratinocyte-fibroblast co-cultures and is antagonistically regulated by endogenous transforming growth factor-beta and interleukin-1. Am J Pathol 2004, 164:2055-2066 